\title{
Optimization of total trihalomethanes (TTHMs) and their precursors's removal by granulated activated carbon (GAC) and sand dual media by response surface methodology (RSM)
}

\author{
Sajida Rasheed ${ }^{1}$, Luiza. C. Campos ${ }^{2}$, Jong. K. Kim³ ${ }^{3}$ Qizhi Zhou² and Imran Hashmi ${ }^{1}$ \\ ${ }^{1}$ Institute of Environmental Sciences and Engineering (IESE), School of Civil and Environmental \\ Engineering (SCEE), National University of Sciences and Technology, NUST, H-12 sector, Islamabad, \\ Pakistan. \\ ${ }^{2}$ Civil Environmental \&Geomatic Engineering Department, University College of London, London \\ WC1E 6BT, UK \\ ${ }^{3}$ Department of Civil Engineering, Kyungnam University, South Korea \\ Correspondent author: sajidarasheed@iese.nust.edu.pk
}

\begin{abstract}
Response surface methodology (RSM) applying central composite design (CCD) with rotatable full factorial (14 non center and 6 center points) was used to discern effect of GAC, sand and $\mathrm{pH}$ on TTHMs and humic acid (HA) removal from drinking water. Results showed efficient TTHMs and HA removal by GAC while sand column showed little effect for TTHMs but significant for TOC removal. With GAC and sand column of $4 \mathrm{~cm}$, a $\mathrm{pH}$ increase from 6 to 8 caused an increase in TTHMs removal from $79.8 \%$ - $83.6 \%$ while a decrease in HA removal from $26.6 \%$ to 6.6\% was observed. An increase in GAC column depth from 10 to $20 \mathrm{~cm}$ caused a slight increase in TTHMs removal from 99.4 to $99.7 \%$, while TOC removal was increased from an average of $38.85 \%$ to $57.4 \%$ removal. The developed quadratic model for TTHMs removal $(p=0.048)$ while linear model for TOC removal $(\mathrm{p}=0.039)$ were significant. GAC column depth $(\mathrm{p}<$ $0.0117)$ and column depth ${ }^{2}(\mathrm{p}<0.039)$ were most significant factors. A $98 \%$ THMs, 30\%TOC and 51\% residual chlorine removal were optimized at $9 \mathrm{~cm} \mathrm{GAC}$ and $4 \mathrm{~cm}$ sand column depth at $\mathrm{pH} 8$ with desirability factor (D) 0.64 .
\end{abstract}

Key words: Chlorine; Drinking water; Humic acid, THMs; Residual chlorine; RSM. 


\section{Introduction:}

Drinking water chlorination containing dissolved organic matter (DOM), mainly humic acids (HA) and fulvic acids (FA) results in disinfection by-products (DBPs) formation (Radian et al. 2011), mainly total trihalomethane (TTHMs) e.g., chloroform $\left(\mathrm{CHCl}_{3}\right)$, bromodichloromethane $\left(\mathrm{CHCl}_{2} \mathrm{Br}\right)$, dibromochloromethane $\left(\mathrm{CHClBr}_{2}\right)$, and bromoform $\left(\mathrm{CHBr}_{3}\right)$. These TTHMs cause kidney, liver cancer, central nervous system damage and miscarriages (Zewdu, 2013). TTHMs Formation in potable water supplies led tighter regulatory control; hence there is a need for proper THM management. Besides TTHMs, DOM removal is itself desirable due to color, taste/odor problems; as biofilm formation accelerator (Razae et al. 2014) and interfering with water treatment.

Water treatment plants remove a specified percentage of DOM to reduce TTHMs formation potential in treatment process and in distribution system (Lekkas et al. 2009). But THMs are hydrophobic and have low molecular weight, making them difficult to be removed by most physiochemical processes (Zewdu 2013). Nano-filtration membranes and reverse osmosis also showed potential in removing THMs (Uyak et al. 2008). However, their application in developing countries is still limited due to the high costs of the membranes and pumping. Therefore adsorption technologies are still widely applied to efficiently remove organic and inorganic pollutant. Among them, granular activated carbon (GAC) adsorption is an effective barrier against many dissolved organic contaminants. Due to the large surface area, its chemistry and fast adsorption kinetics, GAC is recommended by US Environmental Protection Agency for adsorption of these compounds (US-EPA) (Wie et al. 2008).

Nowadays, GAC column adsorbers are used for taste/odor, toxic organics and/or DBP precursor removal (Narbaitz and Karimi-Jashni, 2009). GAC is applied as fixed bed column, water is passed through and organic compounds or contaminants are adsorbed due to intermolecular attraction between dissolved chemicals and GAC surface (Erto et al. 2013). In addition, hydrophobic property of HA makes GAC an adsorbent of choice for HA. GAC as post disinfection is reported to remove residual chlorine besides TTHMs. Chloroform $\left(\mathrm{CHCl}_{3}\right)$ removal was reported around $71.2 \%$ and $76.4 \%$ in deionized and chlorinated water respectively while $100 \%$ residual chlorine was removed when initial chlorine concentration was 0.5 and 0.8 ppm (Samadi et al. 2004). Removal of THMs and DOM (HA+FA) was attributed to adsorption 
while dechlorination was caused catalytically by carbon surface in a pilot study from Athens, Greece (Babi et al. 2007). Lower molecular weight species of HA/FA were more adsorbable, presumably more surface area was accessible to these species (McCreary and Snoeyink, 1980). GAC adsorption capacity can be estimated by fitting Freundlich and Langmuir adsorption isotherms and Freundlich isotherm was fitted well for absorption of chloroform by Zewdu (2011).

Adsorption performance is governed by number of parameters i-e., carbon type, organic matter type, adsorbent particle size, water temperature and $\mathrm{pH}$ (Auta, 2012), $\mathrm{pH}$ being the most influential, inducing not only surface charge to GAC but degree of ionization of contaminant (ElHaddad et al. 2013). Hong (1998) reported that TTHMs adsorption on GAC increased with decreasing $\mathrm{pH}$ from 8.5-5.5. GAC adsorption efficiency has also been reported to vary from chlorinated species to brominated species. The brominated THM compounds were removed more significantly than chlorinated THM ones resulted from the stronger adsorption bonds between the brominated species and GAC (Babi et al. 2011). GAC and sand has also been investigated for TTHMs and their precursor's removal and GAC and sand as a dual media, with $30 \mathrm{~cm}$ GAC and $90 \mathrm{~cm}$ sand depth showed 87\% TTHMs removal (Muhammad et al. 2006).

Although GAC and sand adsorption individually as well as in dual media is reported, their isotherms fitted well but due to the complicity of contaminants, absorber media and treatment processes, the effect of various factors on a process design, performance and their optimization can better be understood by application of mathematical models. These models could establish a mathematical relationship between interacting variable and resulted responses (TTHMs and TOC removal). So the specific objectives of this study were: a) to evaluate the performance of GAC and sand dual media with variable $\mathrm{pH}$ for TTHMs and their precursors's removal, b) to optimize the process using response surface methodology (RSM) and its subsequent modeling for better water distribution system management.

\section{Materials and Methods}

\section{Design of experiment by response surface methodology (RSM)}

RSM was applied for optimization of three effective parameters i.e., GAC and Sand column depths and $\mathrm{pH}$. It provided a new perspective approach for investigating adsorption with better 
results reproducibility, process optimization and predictive model building (Rezaae et al. 2014). In RSM, for each response, a model is defined, predicting individual as well as interactive effect of different parameters with unit factor effect, two factors interaction and quadratic factors's impact on resultant model (Auta, 2012). RSM coupled with central composite design (CCD), is used to study interaction, optimization and modelling of process variables with minimum number of experiments (Danbaba et al. 2015).

Design Expert (DX, Version 9; Stat Ease Inc., Minneapolis, USA) was used for optimum independent parameter design in relation to dependent responses. Design of experiment (DoE) consisted of a rotatable full factorial (14 non center and 6 center points) with various levels of each factor viz $-\alpha,-1,0,+1$ and $+\alpha$ (Table 1) with twenty experimental Runs (Table 3). Experimental sequence was randomized to minimize uncontrolled factors's effect (Salman, 2013). All experiments were performed according to statistical designs to develop predictive regression models used for optimization.

Table 1. Independent variables with low/ high-level by CCD

\begin{tabular}{|c|c|c|c|c|c|c|}
\hline \multicolumn{2}{|c|}{ Coded Values } & $-\boldsymbol{\alpha}$ & $\mathbf{- 1}$ & $\mathbf{0}$ & $\mathbf{+ 1}$ & $+\boldsymbol{\alpha}$ \\
\hline Variables & Symbols & Lowest & Low & Centre & High & Highest \\
\hline GAC depth & A & 0 & 4.0 & 10.0 & 16.0 & 20.0 \\
\hline Sand depth & B & 0 & 4.0 & 10.0 & 16.0 & 20.0 \\
\hline pH & C & 5.32 & 6.0 & 7.0 & 8.62 & 8.68 \\
\hline
\end{tabular}

\section{Determination of surface characteristics of GAC}

Specific surface area, particle size and volume of GAC were determined through Brunauer Emmett Teller (BET) analysis by low temperature nitrogen adsorption method using Micromeritics ASAP 2420 Accelerated Surface Area and Porosimetry System. While scanning electron microscope (SEM; JEOL JSM-6480LV)) was used for GAC surface morphology. 


\section{Standards and reagents}

Prepared TTHM standards (Supelco) with $99.9 \%$ purity $(5000 \mu \mathrm{g} / \mathrm{ml})$ dissolved in methanol were used with Fluorobenzene (FB) $(2000 \mu \mathrm{g} / \mathrm{ml})$ as internal standard. Stock solution of HA (SigmaAldrich) and commercial sodium hypochlorite $(10.5 \%)$ were freshly prepared and applied as per experimental requirement.

\section{Rapid small scale column test}

A fixed bed adsorption system consisted of a small-scale column made up of Plexi glass (internal diameter $=50 \mathrm{~mm}$, height $=30 \mathrm{~cm}$ ), with Teflon cap and stainless steel base was established (Figure 1).

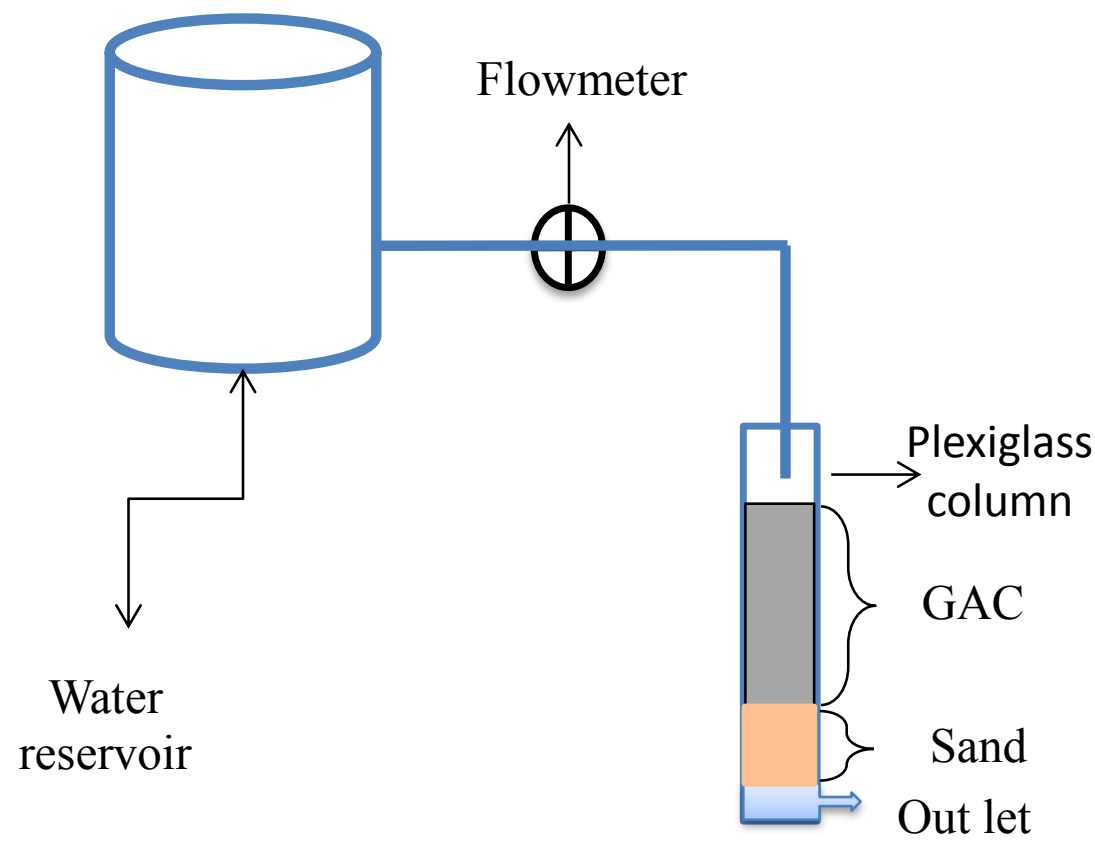

Figure 1. Schematic diagram of the small-scale GAC and sand dual media column

GAC was washed with deionized water and dried at $105^{\circ} \mathrm{C}$ overnight. Feed water containing HA (as precursor) and TTHMs was fed to column in downward direction. Samples were collected with peristaltic pump through silicon tubing from inlet and outlet at different GAC and sand column depths as shown in Table 3. Water $\mathrm{pH}$, temperature and free residual chlorine were measured immediately after sampling by DPD-FAS titrimetric method (APHA, 2005) using Spectroquant Picco colorimeter while TOC was analyzed by TOC analyzer (Shimazdu, TOC-L). 


\section{TTHM extraction and analysis}

TTHM extraction was performed by liquid-liquid extraction (LLE) using Methyl-ter-butyl ether (MtBE; Sigma-Aldrich). In $6 \mathrm{ml}$ of water sample, $0.45 \mathrm{~g}$ sodium sulphate (anhydrous) was added, to enhance organic layer separation, and mixed vigorously for $30 \mathrm{sec}$ followed by addition of $1 \mathrm{ml} \mathrm{MtBE}$, mixed on a vortex mixer for $90 \mathrm{sec}$ and left undisturbed for $160 \mathrm{sec}$. Gas chromatography/mass spectroscopy (GC/MS) (Model Claurus 500, Perkin Elmer) with column (Restek Rxi-5ms, 30mx0.25mmID) was used for TTHMs detection/quantification. GC analytical conditions were: oven temperature was $50{ }^{\circ} \mathrm{C}$ for $5 \mathrm{~min}$; temperature ramp was from $50-180^{\circ} \mathrm{C}$ at the rate of $6^{\circ} \mathrm{C} / \mathrm{min}$, injection volume: $1 \mu 1$.

The percent removal of TTHMs and TOC was calculated as under:

$$
\begin{gathered}
\% \mathrm{R}(\mathrm{TTHMs})=[(\text { Cin-Ceff }) / \mathrm{Cin}] * 100 \\
\% \mathrm{R}(\mathrm{TOC})=[(\text { Cin-Ceff }) / \mathrm{Cin}]^{*} 100
\end{gathered}
$$

Where $\mathrm{C}_{\text {in }}$ is concentration of TTHMs $(\mu \mathrm{g} / \mathrm{L})$ and TOC $(\mathrm{mg} / \mathrm{L})$ in influent water, while $\mathrm{C}_{\text {eff }}$ is concentration of TTHMs $(\mu \mathrm{g} / \mathrm{L})$ and TOC $(\mathrm{mg} / \mathrm{L})$ in effluent water respectively after a known length of column.

\section{Results and Discussion}

\section{Characterization of GAC}

The BET surface area of GAC was $774 \mathrm{~m}^{2} / \mathrm{g}$. The other parameters are given in Table 2 . While SEM image showed ions on GAC surface such as $\mathrm{Ca}^{+2}, \mathrm{Al}^{+3}, \mathrm{O}^{-2}$ and $\mathrm{Si}^{-2}$ (Figure 2). The $\mathrm{Ca}^{+2}$ specifically reported to increasing the capacity of granular activated carbon for adsorption of contaminants as suggested by Daifullah et al. (2004). These cations/anions show greater adsorption capability due to electrostatic forces between carbon surface and contaminant molecules. These "electrostatic attraction" and "surface complex formation" are responsible for efficient adsorption (Radian et al. 2011). These interactions are significantly influenced by $\mathrm{pH}$ (Auta 2012). Sand was Aqua sand with specific density of $2.6 \mathrm{~g} / \mathrm{cm}^{3}$. 
Table 2. BET analysis data

\begin{tabular}{|l|l|l|}
\hline Sr. \# & \multicolumn{1}{|c|}{ Characteristics } & \multicolumn{1}{|c|}{ Value } \\
\hline 1. & Mesh size & $20 * 30$ \\
\hline 2. & GAC particle size & $0.001-0.002 \mathrm{~m}$ \\
\hline 3. & Surface Area & $779.15 \mathrm{~m}^{2} / \mathrm{g}$ \\
\hline 4. & Single point surface area at $\mathrm{P} / \mathrm{Po}$ & 0.30 \\
\hline 5. & BET Surface Area & $774 \mathrm{~m}^{2} / \mathrm{g}$ \\
\hline
\end{tabular}
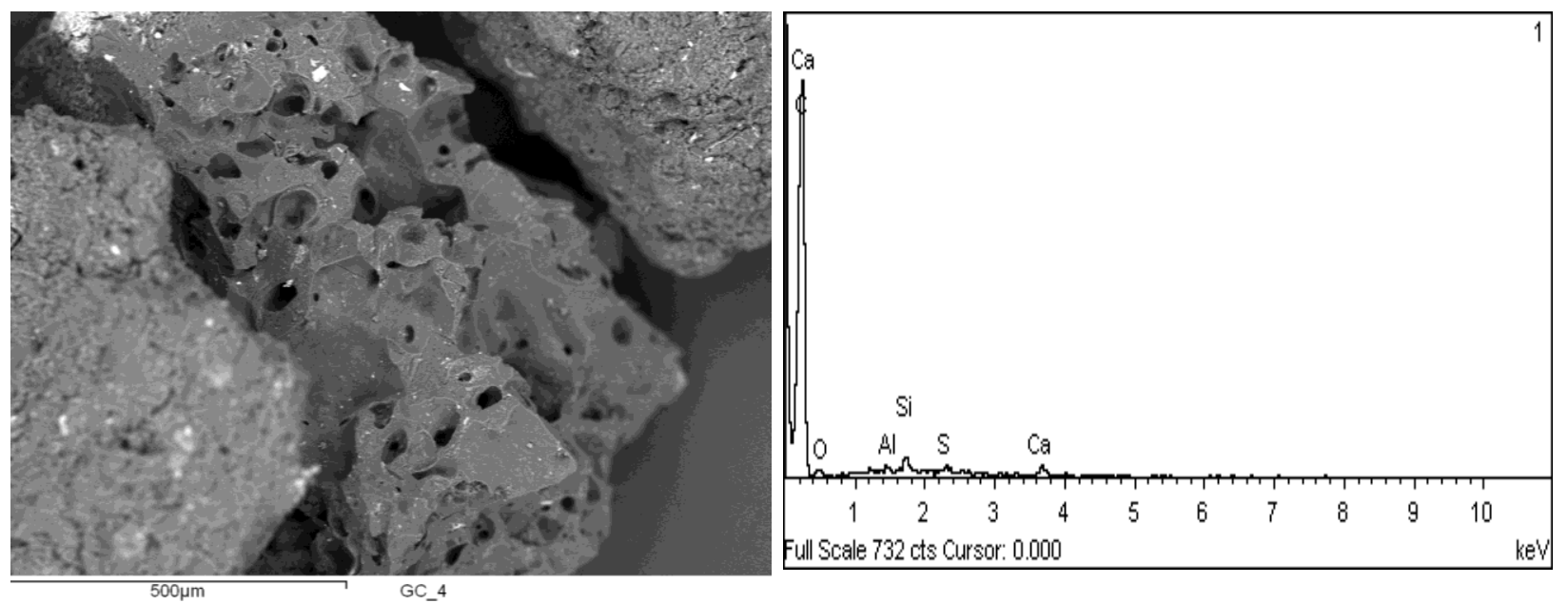

Figure 2. (a) SEM view for GAC surface morphology (b) GAC chemical analysis

\section{TTHMs and their precursors removal by GAC and sand}

For result analysis, optimization, simulation and modelling, Design expert (DX) Version 9 was used. Three parameters i-e., GAC and Sand column depth with pH contributed positively and showed significant TTHMs and HA removal (measured as TOC). The design matrix with actual factors, types of Run and respective responses (TTHMs and TOC removal) are given in Table 3.

It was observed that GAC absorbance was comparatively more significant for TTHMs and TOC than sand. In case of $10 \mathrm{~cm}$ sand column alone, TOC removal was 5.2\%, while TTHMs removal was $2.1 \%$ (Run20). It doubled i-e., $12.6 \%$ for TOC when GAC of same column depth was used 
Table 3. Experimental lay out with respective results

\begin{tabular}{|c|c|c|c|c|c|}
\hline Run & $\begin{array}{c}\text { GAC column } \\
\text { depth }(\mathrm{cm})\end{array}$ & $\begin{array}{c}\text { Sand column depth } \\
(\mathrm{cm})\end{array}$ & $\mathrm{pH}$ & $\begin{array}{c}\text { \% TTHMs } \\
\text { Removal }\end{array}$ & $\begin{array}{c}\text { \% TOC } \\
\text { Removal }\end{array}$ \\
\hline 1 & 10.0 & 20.1 & 7.0 & 97.7 & 19.5 \\
\hline 2 & 10.0 & 10.0 & 7.0 & 99.3 & 27.5 \\
\hline 3 & 4.0 & 16.0 & 6.0 & 86.1 & 18.3 \\
\hline 4 & 16.0 & 4.0 & 8.0 & 97.0 & 57.2 \\
\hline 5 & 4.0 & 4.0 & 6.0 & 79.8 & 26.5 \\
\hline 6 & 20.1 & 10.0 & 7.0 & 99.7 & 57.4 \\
\hline 7 & 10.0 & 10.0 & 7.0 & 99.4 & 75.5 \\
\hline 8 & 10.0 & 10.0 & 7.0 & 99.5 & 35.7 \\
\hline 9 & 10.0 & 10.0 & 5.32 & 86.9 & 28.5 \\
\hline 10 & 10.0 & 10.0 & 7.0 & 99.6 & 32.9 \\
\hline 11 & 4.0 & 4.0 & 8.0 & 83.6 & 6.6 \\
\hline 12 & 10.0 & 10.0 & 7.0 & 99.4 & 29.2 \\
\hline 13 & 10.0 & 10.0 & 7.0 & 99.6 & 31.1 \\
\hline 14 & 10.0 & 0.0 & 7.0 & 89.0 & 12.6 \\
\hline 15 & 16.0 & 16.0 & 6.0 & 94.9 & 46.7 \\
\hline 16 & 10.0 & 10.0 & 8.68 & 99.7 & 31.4 \\
\hline 17 & 4.0 & 16.0 & 8.0 & 81.4 & 16.1 \\
\hline 18 & 16.00 & 16.0 & 8.0 & 98.9 & 58.7 \\
\hline 19 & 16.0 & 4.0 & 6.0 & 99.0 & 63.0 \\
\hline 20 & 0.0 & 10.0 & 7.0 & 2.1 & 5.2 \\
\hline
\end{tabular}

(Run 14) while TTHMs removal was also significantly increased up to $89.0 \%$ (Table 3). The reason could be the adsorbent kind as sand showed less attraction for TOC and TTHMs than GAC. On the other hand, increasing the GAC column depth resulted in more efficient TTHMs and TOC removal simultaneously. Amount of TTHMs adsorbed was observed to be correlated to stronger surface hydrophobicity of adsorbent (Nakamura et al. 2006) and was proportional to available GAC surface. For pH 7, there was a significant increase in TTHMs removal from 2.1 
(run 20) from the top of the GAC to $99.7 \%$, to $20 \mathrm{~cm}$ depth of GAC (run 6) (Table 3). While an increase in GAC column depth from 10 to $20 \mathrm{~cm}$ caused a small increase in TTHMs removal from 99.4 (run 7) to $99.7 \%$ (run 6), while TOC removal was increased from an average of 38.85 $\%$ (Run 7-10 \& 12,13) to 57.4\% removal (Run 6). When pH was increased from 6 to 8 with GAC and sand depth of $4 \mathrm{~cm}$, TTHMs removal was increased from $79.8 \%$ (Run 5) to $83.6 \%$ (Run 11) while TOC adsorption was decreased from $26.6 \%$ to $6.6 \%$. This decrease could be reasoned as by increasing $\mathrm{pH}$, GAC particles tend to adsorb negative charges and $\mathrm{HA}$ are negatively charged naturally so reduced electrostatic attraction resulted in less adsorption, emphasized by Al-Nesseri and Abbas (2009).

To analyze combined effect of three factors on TTHMs removal, three-dimensional (3-D) surface plots and contour graphs were employed (Figure 3a \& 3b) which are the graphical representation of regression equation. In Figure 3 (a) the legend X1 (x-axis) and X2 (y-axis) show GAC and $\mathrm{pH}$ respectively and curvature and color from blue to red in contour graph (Figure 3b, X1 (x-axis) = GAC, X2 (y-axis) $=$ Sand) revealed that removal of TTHMs increased up to a certain limit (99.7\%) (Run 6) with increasing GAC layer length up to $20 \mathrm{~cm}$, then decreased. This may be due to the saturation of the adsorptive site on GAC.

\section{Statistical data analysis for GAC removal}

Data competence and significance of the model was assessed by analysis of variance (ANOVA) (Chaudhary et al. 2012). A significant quadratic model was fitted with a $p$ value of 0.0486 with GAC column depth being the most significant factor $(\mathrm{p}=0.0117)$ (Table 4$)$. Beside $p$, determination of coefficient $\left(R^{2}\right)$ and adjusted $R^{2}$ (adjust. $R^{2}$ ) were also used as statistical tool to evaluates model adequacy (Razaee et al. 2014). Closer the $\mathrm{R}^{2}$ value to unity and smaller standard deviation (16.67), better the model in predicting response (Danbaba et al. 2015). The values of $\mathrm{R}^{2}$ and adjust. $\mathrm{R}^{2}$ were 0.73 and 0.49 respectively. The statistical results showed that model was well defined to predict the TTHM removal within the range of variables applied. 

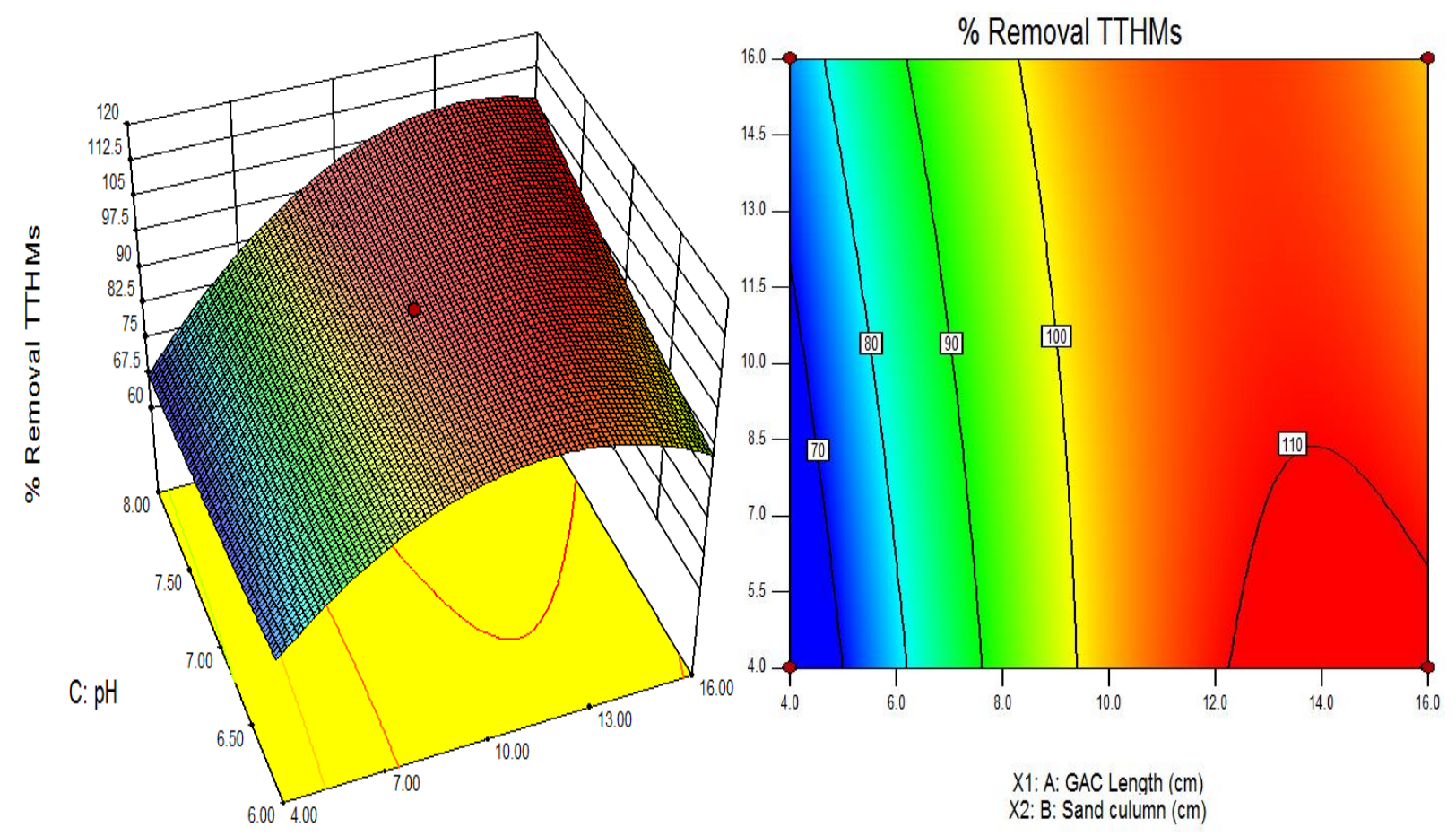

Figure 3. 3-D response and 2-D contour surface graph showing the effect of GAC layer depth on TTHMs removal

Table 4. ANOVA for TTHMs removal

\begin{tabular}{|c|c|c|c|c|c|}
\hline Source & $\begin{array}{c}\text { Sum of } \\
\text { Squares }\end{array}$ & Df & $\begin{array}{c}\text { Mean } \\
\text { Square }\end{array}$ & F Value & P Value \\
\hline Model & 7629.56 & 9 & 47.73 & 3.05 & 0.0486 \\
\hline A-GAC Length & 2634.64 & 1 & 2634.64 & 9.48 & 0.0117 \\
\hline B-Sand Length & 141.07 & 1 & 141.07 & 0.51 & 0.4925 \\
\hline C-pH & 137.00 & 1 & 137.00 & 0.49 & 0.4987 \\
\hline AB & 288.71 & 1 & 288.71 & 1.04 & 0.3322 \\
\hline AC & 252.42 & 1 & 252.42 & 0.91 & 0.3631 \\
\hline
\end{tabular}




\begin{tabular}{|c|c|c|c|c|c|}
\hline $\mathrm{BC}$ & 157.38 & 1 & 157.38 & 0.57 & 0.4691 \\
\hline $\mathrm{A}^{2}$ & 3882.78 & 1 & 3882.78 & 13.97 & 0.0039 \\
\hline $\mathrm{B}^{2}$ & 3.26 & 1 & 3.26 & 0.012 & 0.9158 \\
\hline $\mathrm{C}^{2}$ & 8.33 & 1 & 8.33 & 0.030 & 0.8660 \\
\hline Residuals & 2779.76 & 10 & 277.98 & ------- & ---- \\
\hline Lack of fit & 2779.54 & 5 & 555.91 & 11130.13 & $<0.0001$ \\
\hline Pure error & 0.23 & 5 & 0.046 & $\begin{array}{ll}----- \\
\end{array}$ & $\begin{array}{ll}---- \\
\end{array}$ \\
\hline Cor. total & 10409.32 & 19 & ------ & ------ & ----- \\
\hline St. Dev. & 16.67 & & & R-Squared & $\mathbf{0 . 7 3 3 0}$ \\
\hline Mean & 89.20 & & & Adj. R-squared & 0.4926 \\
\hline C. V \% & 18.69 & & & Pred.R- Squared & -1.0805 \\
\hline
\end{tabular}

\section{Efficiency of sand for the TOC removal}

The adsorption of TTHMs and HA on sand occurs due the bonding between oxygen atoms on sand surface and the hydroxyl radical present on TTHMs and HA (Site, 2001). The 3D surface plots depicted TOC removal behavior by GAC and $\mathrm{pH}$ (Figure 4a) and by sand and GAC dual media column (Figure 4b). From Figure 4 (a) it is evident that $\mathrm{pH}$ showed no appreciable effect on TOC absorption as removal percentage remained almost constant from $\mathrm{pH} 6$ to 8 on $\mathrm{x}$-axis. These results are in accordance with Erto et al. (2013) who reported a negligible effect of pH on GAC adsorption for TOC. While increasing GAC column length (y-axis) the percent TOC removal increases up to almost 52\%. In Figure $4 \mathrm{~b}$, as expected, sand column showed a slight TOC removal (almost 15\%) represented as B on y-axis as compared to GAC (Approximately $52 \%$ ) at GAC column length of $16 \mathrm{~cm}$ (A: $\mathrm{x}$-axis). 

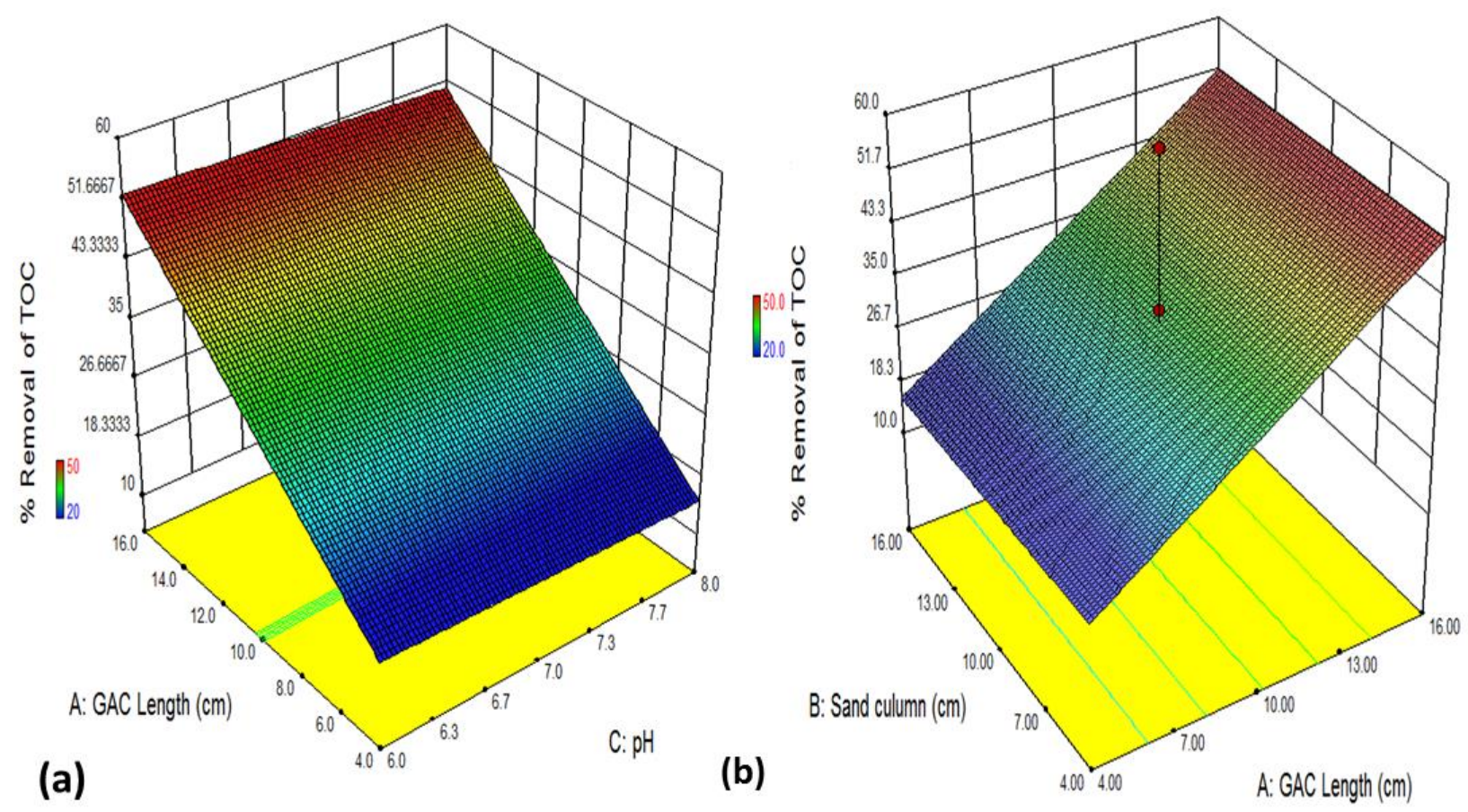

Figure 4. 3-D response surface graphs showing effect of (a) GAC and pH on TOC removal

(b) GAC and sand column depth on TOC removal

While in Figure 4 (b), GAC demonstrated linear effect for TOC removal as by increasing GAC column depth, TOC removal increased proportionally. Therefore it was evaluated that Sand column showed a less efficient effect on TOC removal as compared to GAC.

\section{Statistical data analysis for TOC removal}

In case of TOC removal, a linear model was fitted to data which was significant $(p=0.0018)$ with GAC column depth again was the most significant factor $(\mathrm{p}=0.011)$ (Table 5). The $\mathrm{R}^{2}$ for the model was approximately 0.60 while pred. $\mathrm{R}^{2}$ was 0.524 . A very high $\mathrm{F}$-value $(\mathrm{F}$ model=7.98, much greater than unity) and a very low probability value $(\mathrm{p}=0.0018)$ with small standard deviation $(\mathrm{SD}=13.61$ ) indicated that model obtained is appreciably significant (Appovoo et al. 2014). 
Table 5. ANOVA Table for TOC removal with linear model

\begin{tabular}{|c|c|c|c|c|c|}
\hline Source & $\begin{array}{l}\text { Sum of } \\
\text { Squares }\end{array}$ & Df & $\begin{array}{l}\text { Mean } \\
\text { Square }\end{array}$ & F Value & $\begin{array}{l}\text { P Value } \\
\text { Prob. }>\text { F }\end{array}$ \\
\hline Model & 4435.94 & 3 & 1478.65 & 7.98 & 0.0018 \\
\hline $\begin{array}{l}\text { A-GAC } \\
\text { Length }\end{array}$ & 4426.45 & 1 & 4426.45 & 23.90 & 0.0002 \\
\hline B-Sand Length & 0.28 & 1 & 0.28 & 1.526-E003 & 0.9693 \\
\hline C-pH & 9.21 & 1 & 9.21 & 0.050 & 0.8264 \\
\hline Residuals & 2963.93 & 16 & 185.25 & ------ & ---- \\
\hline Lack of fit & 1297.45 & 11 & 117.95 & 0.35 & 0.9298 \\
\hline Pure error & 1666.49 & 5 & 333.30 & ------ & ------ \\
\hline Cor. total & 7399.87 & 19 & ----- & ------ & ----- \\
\hline St. Dev. & 13.61 & & & R-Squared & 0.5955 \\
\hline Mean & 33.97 & & & Adj. R-squared & 0.5244 \\
\hline C. V \% & 18.69 & & & Pred. R-Sq & 0.4418 \\
\hline PRESS & 4130.27 & & & Adeq.Precision & 9.949 \\
\hline
\end{tabular}

\section{Efficiency of GAC for residual chlorine removal}

According to literature, GAC removes chlorine by reduction (Babi et al. 2011). The trend of Figures $5(\mathrm{a} \& \mathrm{~b})$ showed that by increasing GAC and sand column individually and together, increase in residual chlorine removal was observed. The curvature in 3-D surface showed a 
minimum removal at $4 \mathrm{~cm}$ depth of each column and increased as column depth increased (Figure 5a) and triggered catalytically by carbon surface (Babi et al. 2011).

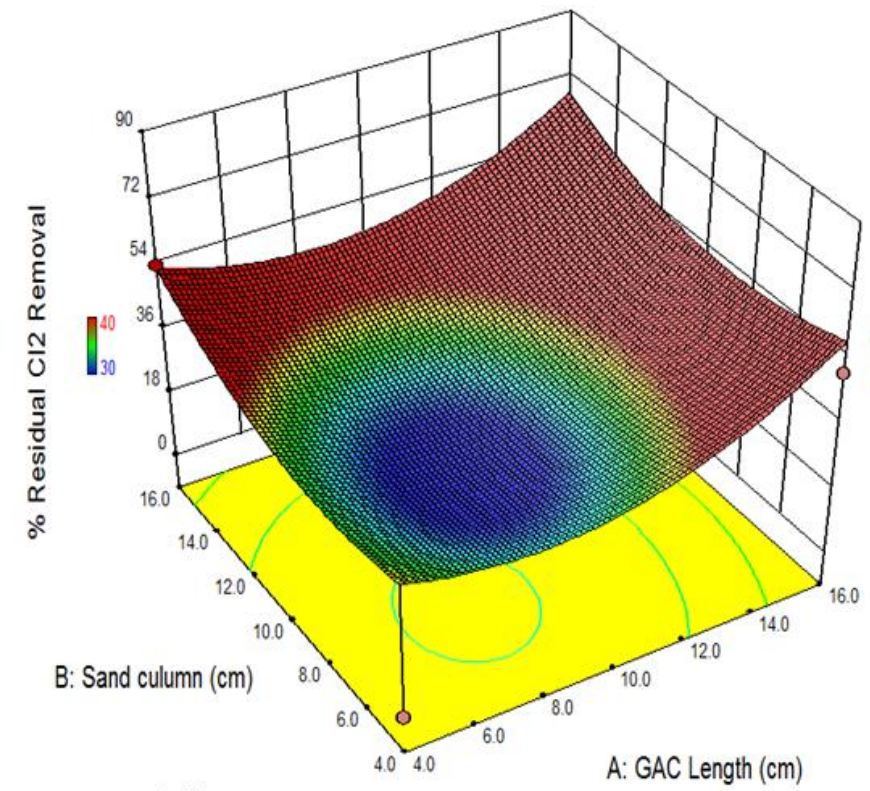

(a)

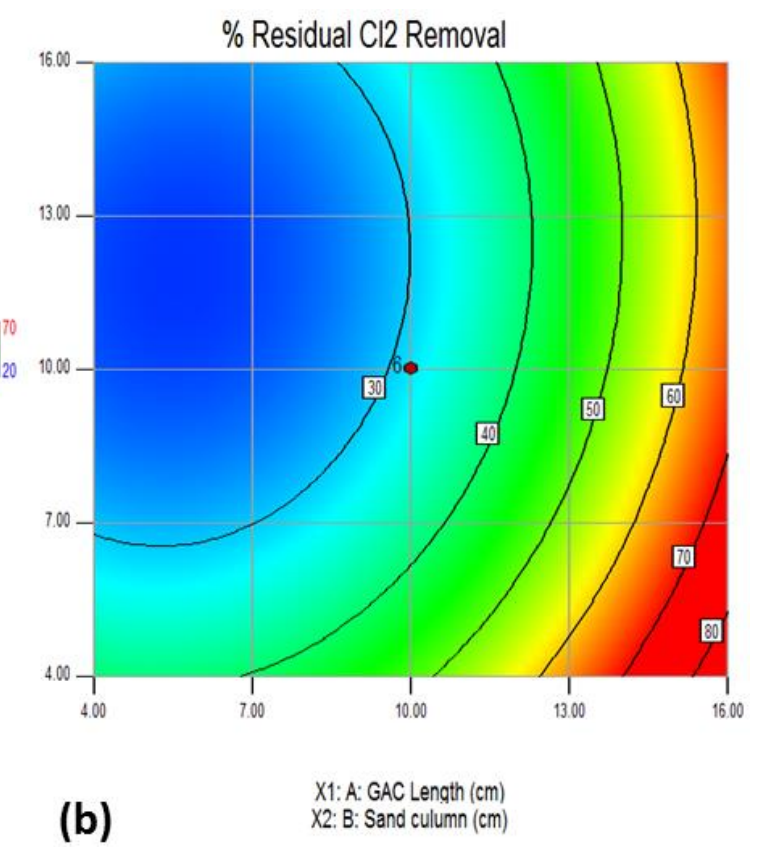

Figure 5. (a) 3-D response surface graph (b) 2-D contour graph showing effect of GAC/ Sand column depth on residual chlorine removal

While Zewdu (2013) reported that chlorine reduction occurred in top few centimeters of GAC column, while present study showed that for residual chlorine removal, both GAC and sand column were more or less equally effective and huge part of it was removed from feed water.

\section{The Pareto chart of variables}

To observe contribution of most significant factor towards effective removal of TTHMs, TOC and residual chlorine, Pareto chart of variables was plotted, (Figure 6). Here bar lengths are proportional to value of effect, showing their relative importance (Tuncel and Topal, 2011). In this chart, maximal effect was presented in upper portion then progresses down to minimal effect. A, B, and C are coefficients with one factor for GAC column depth, sand column depth and $\mathrm{pH}$, respectively, while the coefficients with two factors $(\mathrm{AB}, \mathrm{BC}, \mathrm{AC})$ and with secondorder polynomials $\left(\mathrm{A}^{2}, \mathrm{~B}^{2}\right.$ and $\left.\mathrm{C}^{2}\right)$ terms show interaction between two factors and quadratic effect, respectively (Chaudhary et al. 2012). The chart shows that almost $48 \%$ removal was contributed by GAC column depth $\left(\mathrm{A}^{2}\right)$. 


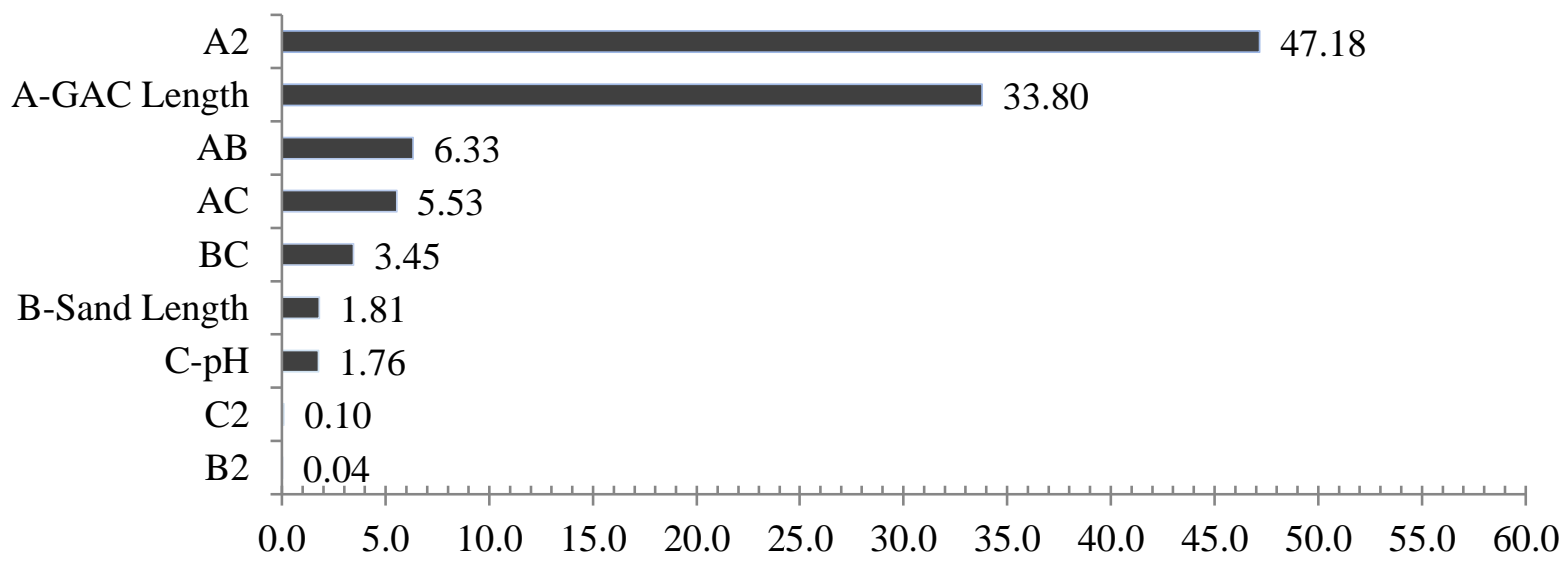

Figure 6. Pareto chart showing contribution of variables for THMs removal

\section{Evaluation of the model}

The adequacy of model was tested by correlation between normal plots of residuals versus percent removal of TOC and TTHMs respectively as shown in Figure 7 (a\&b) (Singh et al. 2011). It is also used to validate accuracy of the predictive model. The Figures depicted a fairly good correlation between the obtained results and predicted values by statistical model and a reasonable agreement between observed data and determined values was observed indicating suitability of model.

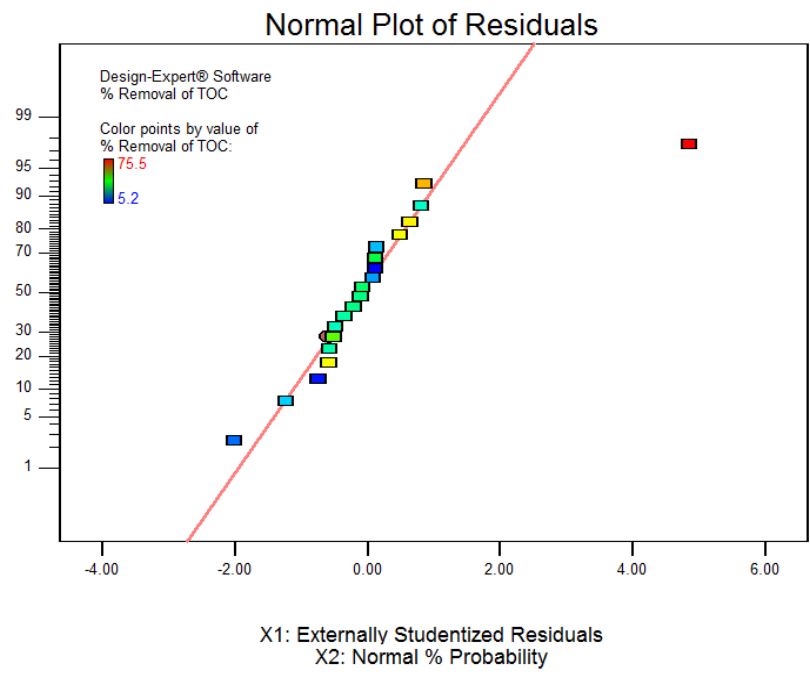

Figure 7. (a) Normal plot residuals for TOC

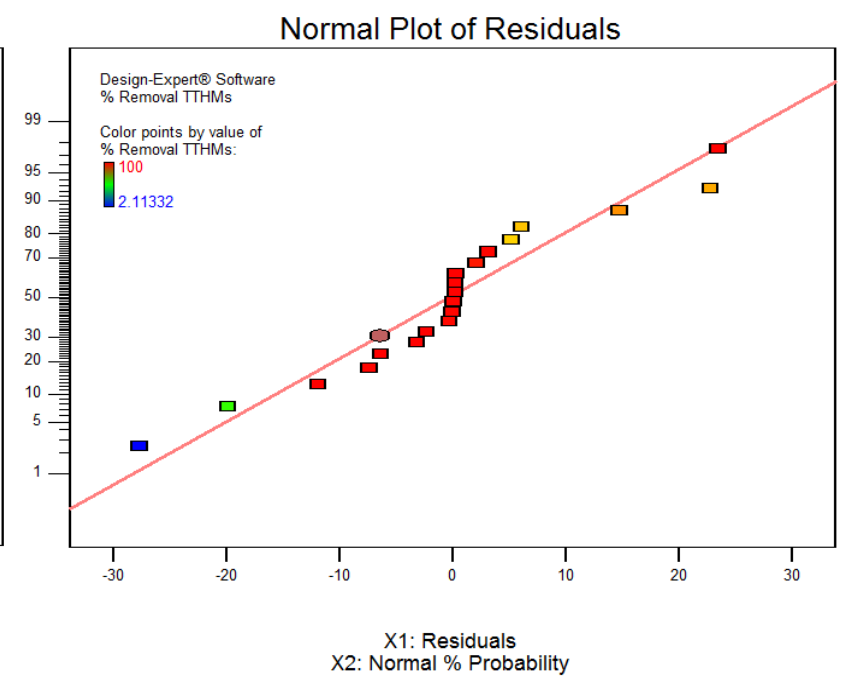

(b) Normal plot of residuals for TTHMs 
The data points are aligned on the diagonal depicting that fitted regression equation showed a satisfactorily good fit for the model using RSSCT (Appavoo et al. 2014).

\section{TTHMs's removal modelling}

In $\mathrm{RSM} / \mathrm{CCD}$, each response was used to develop an empirical model that correlates response (percent TTHMs and TOC removal) to three studied factors i.e., GAC, sand and $\mathrm{pH}$. Based on quadratic polynomial equation (suggested by the software) and Normal plots of residuals, empirical relationship between independent variables and percent removal of TTHMs and TOC may be expressed as a mathematical model equation given below.

TTHMs Removal \%=99.56-16.41A $\mathrm{A}^{2}-6.01 \mathrm{AB}+5.62 \mathrm{AC}+4.44 \mathrm{BC}$

Where:

$\mathrm{A}=\mathrm{GAC}$ column depth

$\mathrm{B}=$ Sand column depth

$\mathrm{C}=\mathrm{pH}$

Based on the evaluation of the data by Normal plot of residuals, it is estimated that the model had good prediction effect for the removal of TTHMs and HA TOC. This mathematical model may be used to predict performance of fixed bed GAC and sand column to remove/reduce TOC and TTHMs from drinking water (Danbaba et al., 2015). Although the other water quality parameters may vary, the use of natural water instead of one-solute solution is considered to make no significant difference to model prediction by activated carbon filtration (Babi et al. 2011).

\section{Numerical and graphical optimization}

Process optimization is important in determining values of factors for which response is at maximum (Sagbas, 2011) by solving regression equation. So removal efficiency became objective function or performance index called as desirability function (D), whose value closer to 1 is considered fair enough. For Numerical optimization, the goal is to optimize all variables altogether for a numeric value for collective response (percent TTHMs and TOC removal). 


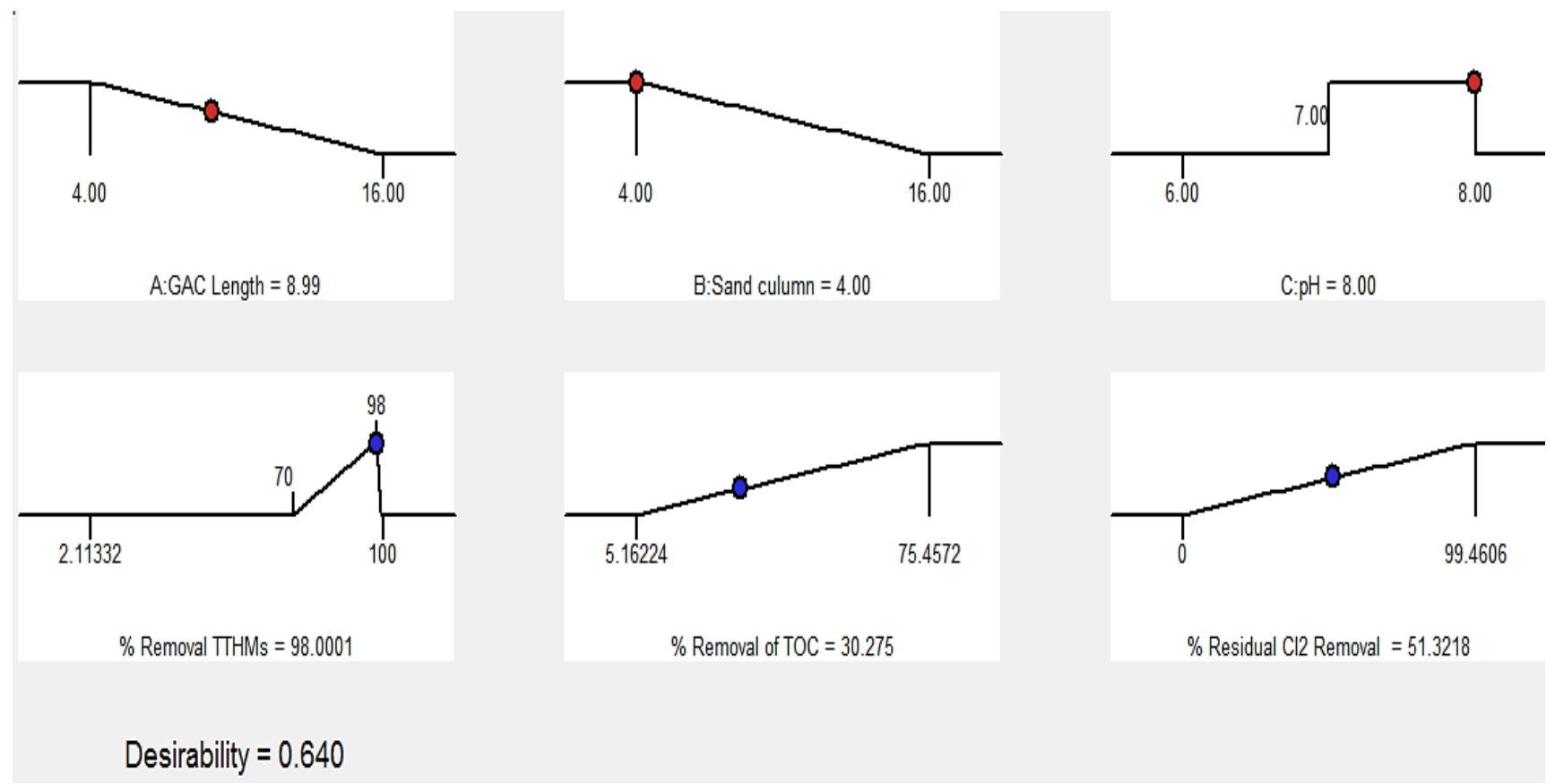

Figure 8. Ramp function for 98\% removal of THHMs $30 \%$ TOC and 51\% residual chlorine

Numerical optimization was done for maximum removal of TTHMs, TOC and residual chlorine with minimum GAC and sand column depth (0 to $20 \mathrm{~cm}$ ) and an optimized $\mathrm{pH}$ (pH 5.32 to 8.68) (ranges given in Table 1). This will reduce capital costs related to columns and operational costs related to $\mathrm{pH}$ correction. The top row in Figure 8 depicted recommended factor settings, and predicting responses are shown in second row. The model predicted $98 \%$ TTHMs, 30\% TOC removal and 51\% residual chlorine removal which could be achieved simultaneously at $9 \mathrm{~cm}$ GAC and $4 \mathrm{~cm}$ of sand depth as dual media with a $\mathrm{pH}$ value of 8 with $\mathrm{D}=0.64$ (Figure 8).

The maximum predicted value for TTHMs and TOC removal for independent variables ranges may also be represented graphically by graphical optimization (Figure 9). The surface confined in the smallest eclipse colored as yellow region, in the contour diagram, illustrated the area where all the variables meet required criteria (Trinh and Kang, 2010). The grey part depicts the areas where only a part of criteria is met. 


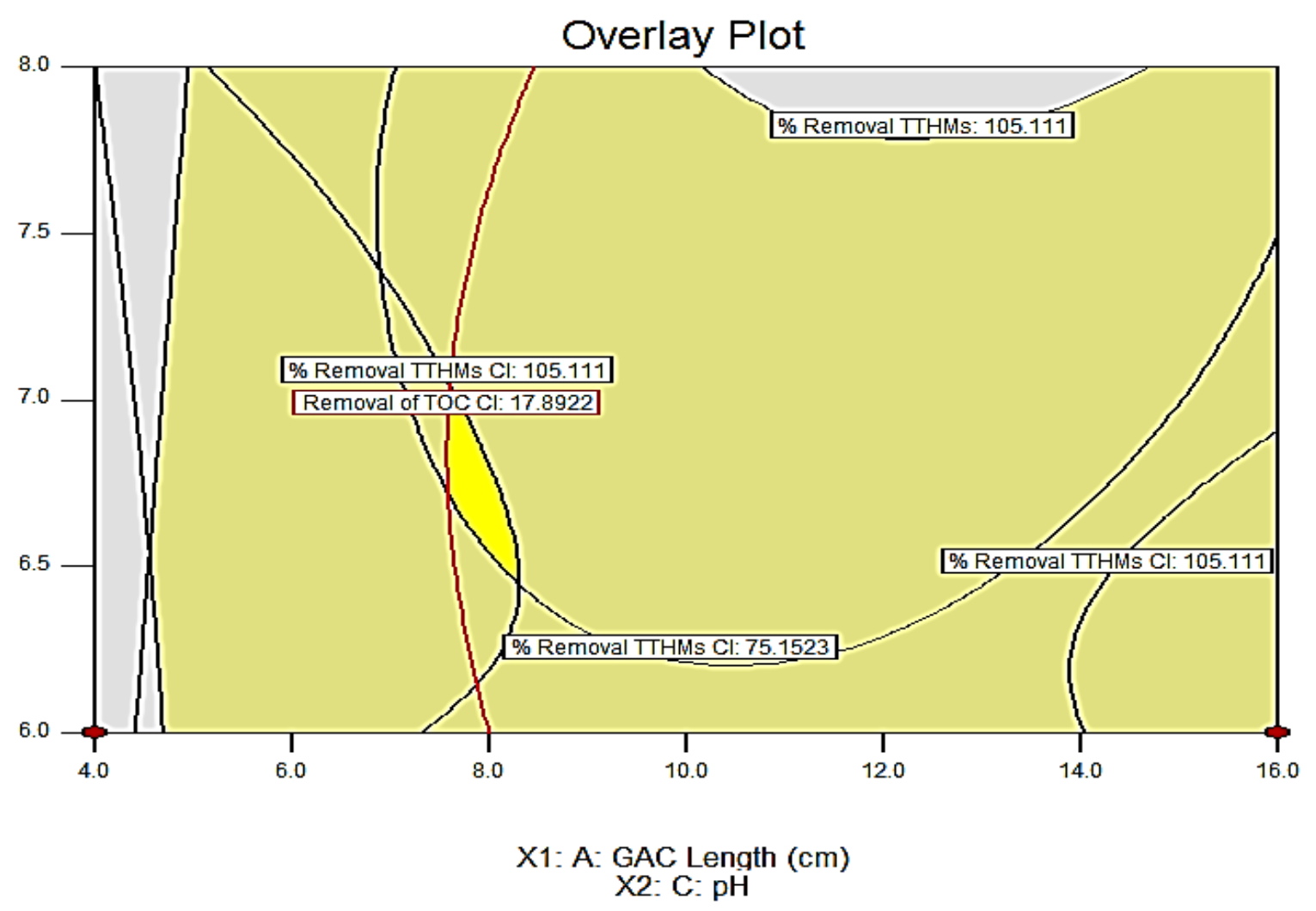

Figure 9. Overlain plot of TTHMs and TOC removal

\section{Conclusions and recommendations}

The present study was conducted to optimize and model various factors for maximum TTHMs removal from water using GAC and sand dual media using RSM coupled with CCD.

The following conclusions may be drawn:

1. TTHMs removal increased with increase in $\mathrm{pH}(\mathrm{p}<0.48)$ while a decrease in HA removal from $26.6 \%$ to $6.6 \%$ was observed $\mathrm{pH}$ at GAC and sand dual column of $4 \mathrm{~cm}$ each.

2. With increasing GAC column depth, TOC removal increased due to increase in number of binding site irrespective of high $\mathrm{pH}$.

3. Maximum TTHMs and TOC removal was $99.7 \%$ and $57.4 \%$ respectively at GAC and sand column depth of $20 \mathrm{~cm}$ and $10 \mathrm{~cm}$ respectively at $\mathrm{pH} 7$.

4. Quadratic model for TTHMs removal was significant $(p=0.048)$ with $R^{2}=0.73$ while linear model for TOC removal with $\mathrm{p}=0.0018$ and $\mathrm{R}^{2}=0.59$. 
5. GAC column depth $(p<0.0117)$ and column $\operatorname{depth}^{2}(p<0.039)$ were most significant factors for both TTHMs and TOC removal while sand showed less significant effect for TTHMs removal.

6. A $98 \%$ TTHMs, 30\% TOC and 51\% residual chlorine removal was optimized at GAC and sand column depth of $9 \mathrm{~cm}$ and $4 \mathrm{~cm}$ respectively at $\mathrm{pH} 8$ with $\mathrm{D}=0.64$.

Based upon conclusions, a detailed study at a pilot plant is suggested for further insight into removal efficiency. Furthermore treatment performance to remove these contaminants should be evaluated using the specific water of the area to be treated.

\section{References:}

Al-Naseri, S. K. and Abbas, T. R. 2009 Predicting NOM removal by fixed-bed GAC adsorbers. Jordan Journal of Civil Engineering, 3 (2), 172-183.

APHA 2005 Standard Methods for the Examination of Water and Wastewater. (Washington: American Public Health Association).

Appavoo, I, A., Hu , J. O., Huang, Y., Li, S. M. Y., Ong, S. L. 2014 Response surface modeling of Carbamazepine (CBZ) removal by Graphene-P25 Nano composites/UVA process using central composite design. Water Research, 57, 270-279.

Auta, M. 2012 Optimization of tea waste activated carbon preparation parameters for removal of cibacron yellow dye from textile waste waters. International Journal of Advanced Engineering Research and Studies, 1 (4), 50-56.

Babi, K. G., Koumenides, K.M., Makri, C.A. and Lekkas, T.D. 2011 Adsorption capacity of GAC pilot filter-adsorber and post filter- Adsorber for individual THMs from drinking water, Athens. Global NEST Journal, 13(1), 50-58.

Corwin, C. J. and Summer, R. S. 2012 Controlling trace organic contaminants with GAC adsorption. American Water Works Association. E36-E47. Corwin \& Summers । http://dx.doi.org/10.5942/jawwa.2012.104.0004Journal. 
Chowdhury, Z.Z., Zain, S. M., Khan, R. A., Ahmad, A. A. and Khalid, K. 2012 Application of response surface methodology (RSM) for optimizing production condition for removal of $\mathrm{Pb}$ (ii) and CU (ii) onto Kenaf fiber based activated carbon. Research Journal of Applied Sciences Engineering and Technology, 4 (5), 458-465.

Daifullah, A. A. M., Girgis, B. S. and Gad, H. M. H. 2004 A study of the factors affecting the removal of humic acid by activated carbon prepared from biomass material. Colloids and Surfaces A: Physicochemical and Engineering Aspects, 235 (1-3), 1-10.

Danbaba, N., Nkama,I. and Badau, M. H. 2015 Application of Response Surface Methodology (RSM) and Central Composite Design (CCD) to Optimize Minerals Composition of Rice Cowpea Composite Blends during Extrusion Cooking. International Journal of Food Science and Nutrition Engineering, 5 (1), 40-52. DOI: 10.5923/j.food.20150501.06

Erto., A., Lancia, A. and Musmarra, D. 2013 Fixed-bed adsorption of Trichloroethylene onto activated carbon. Chemical Engineering Transactions, 34, 1969-1974.

Hong, S.1998 The role of $\mathrm{pH}$ and initial concentration on GAC absorption for removal of natural organic matter. Environmental Engineering Research, 3(4), 183-190.

El-Haddad, M., Slimani, R., Mamouni, R., Elantri, S. and Lazar, S.2013 Removal of two textile dyes from aqueous solution onto calcined bones. Journal of the Association of Arab Universities for Basic and Applied Sciences, 14, 51-59.

Lekkas, T. D., Babi, K. G., Koumenides, K. M., Makri, C. A., Lekkas, D. T and Nikolaou, A. D. 2009 Removal of specific DBPs by GAC in Galatsi WTP, Athens. Global NEST Journal, 11 (3), 349-356

McCreary, J. J. and Snoeyink, V. L. 1980 Characterization and activated carbon adsorption of several humic substances. Water Research, 14(2), 151-160. 
Mohammed, M. A., Hassan, A. H., EL-Messiry, M.A. and Hazzaa, R. A. 2006 Removal of Trihalomethanes by dual filtering media (GAC-Sand) at El-Manshia water purification plant. The Journal of the Egyptian Public Health Association (JEPHAss), 81 (3 \& 4), 241-258.

Nakamura, T., Kawasaki, N., Araki, M., Yoshimura, K. and Tanada, S. 2001 Trihalomethane removal by activated carbon fiber. Journal of Environmental Science and Health, Part A: Toxic/Hazardous Substances and Environmental Engineering, 36 (7), 1303-1310.

Radian, A., Carmeli, M., Zadaka-Amir, D., Nir, S., Wakshal, E. and Mishael, Y. G. 2011 Enhanced removal of humic acid from water by micelle-montmorillonite composites: Comparison to granulated activated carbon. Applied Clay Science, 54, 258-263.

Rezaee, R., Maleki, A., Jafari, A., Mazloomi,S., Zandsalimi, Y. and Mahvi, A. H. 2014 Application of response surface methodology for optimization of natural organic matter degradation by UV/H2O2 advanced oxidation process. Journal of Environmental Health Science \& Engineering, 12, 67.

Sagbas, A. 2011 Analysis and optimization of surface roughness in the ball burnishing process using response surface methodology and desirabilty function. Adv. in Engg. Software. 42, 992998.

Samadi, M. T., Nasseri, S., Mesdaghinia, A. R. and Alizadefard, M. R.2004 Removal of chloroform $\left(\mathrm{CHCl}_{3}\right)$ from Tehran drinking water by $\mathrm{GAC}$ and air stripping columns. Iranian Journal of Environmental Health Science \& Engineering, 1 (1), 5-11.

Singh, K. P., Gupta, S., Singh, A.K. and Sinha, S. 2011 Optimizing adsorption of crystal violet dye from water by magnetic Nano composite using response surface modeling approach. Journal of Hazardous Material, 186 (2-3), 1462-1473.

Site, A. D. 2001 Granulated activated carbon adsorption. J. Phys. Chem. American Institute of Physics, 30 (1), 187-253. 
Trinh, T. K. and Kang, L. S. 2010 Application of response surface method as an experimental design to optimize coagulation tests. Environmental Engineering Research, 15(2), 63-70.

Tuncel, S. G. and Topal, T. 2011 Multifactorial optimization approach for determination of polycyclic aromatic hydrocarbons in sea sediments of Turkish Mediterranean Coast. American Journal of Analytical Chemistry, (AJAC), 2, 783-794.

Uyak, V.,Koyuncu, I., Oktem, I., Cakmakci, M and Toroz, I (2008). Removal of trihalomethanes from drinking water by nanofiltration membranes. Journal of Hazardous Materials. 152 (2): 789-794.

Wei, L. L., Zhao, Q. L., Xue, S. and Jia, T.2008 Removal and transformation of dissolved organic matter in secondary effluent during granular activated carbon treatment. J Zhejiang University Sci A, 9(7), 994-1003.

Zewdu, T. Z. 2013 Multi-objective application of granular activated carbon in the production of carbonated beverage process water and bottled water. International Journal of Physical Sciences, 8(16), 689-698.

Zewdu, T. 2011 GAC adsorption processes for chloroform removal from drinking water. Tanzania Journal of Natural and Applied Sciences (TaJONAS), 2(1), 352-358. 